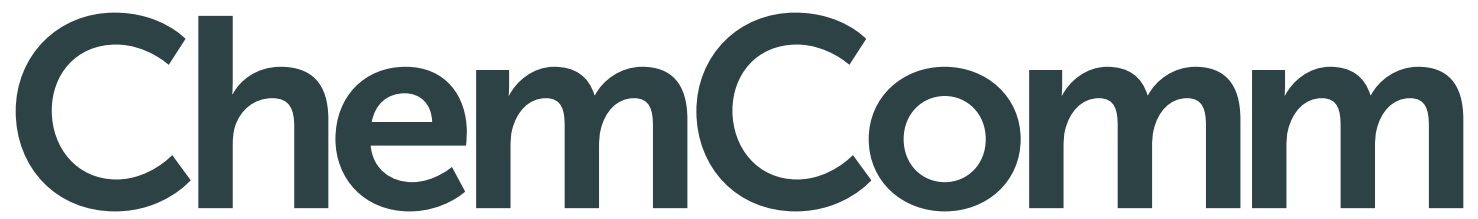

Chemical Communications rsc.li/chemcomm

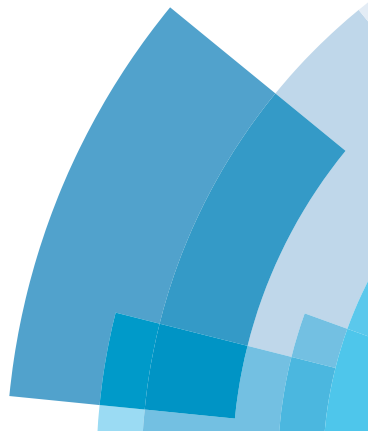

$\cdot$

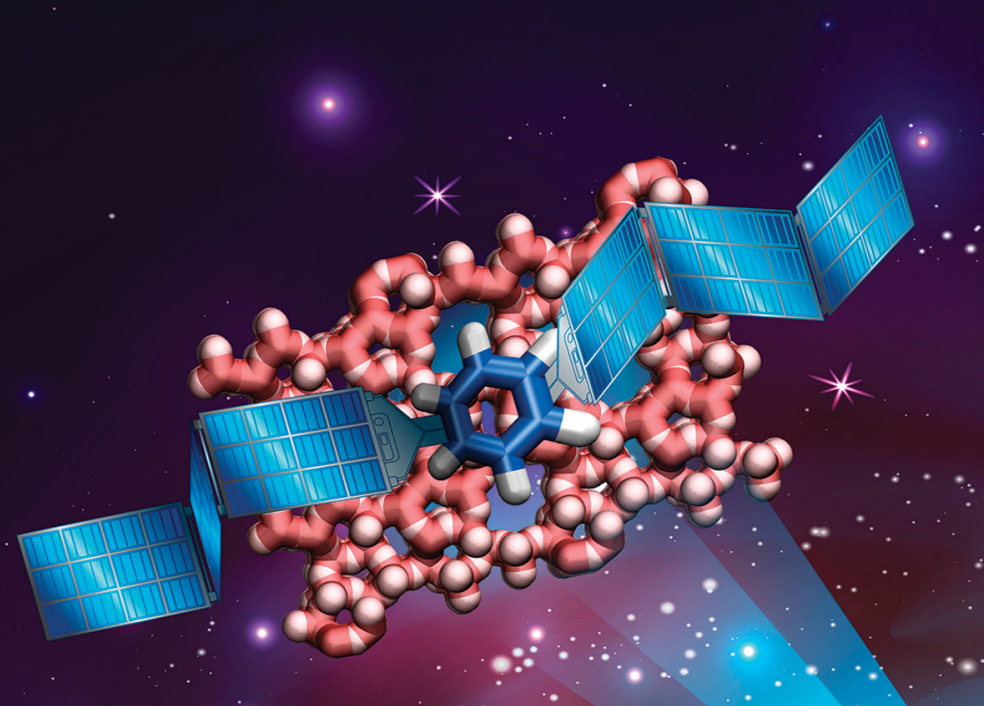

$\cdot$

$\because \quad \therefore \quad \therefore \quad \therefore$ 
Check for updates

Cite this: Chem. Commun., 2017, 53, 13012

Received 31st August 2017, Accepted 23rd October 2017

DOI: $10.1039 / \mathrm{c} 7 \mathrm{cc} 06832 \mathrm{~h}$

rsc.li/chemcomm

\section{Nanoscale infrared imaging of zeolites using photoinduced force microscopy $\dagger$}

\author{
Donglong Fu, (D) ${ }^{a}$ Katie Park, (D) ${ }^{b}$ Guusje Delen, (D) a Özgün Attila, (D) ${ }^{a}$ \\ Florian Meirer, (D) ${ }^{a}$ Derek Nowak, (D) ${ }^{b}$ Sung Park, (D) ${ }^{b}$ Joel E. Schmidt (D) ${ }^{a}$ and \\ Bert M. Weckhuysen (D)*a
}

\begin{abstract}
Characterizing the structures of zeolites and their catalytic performance with high-spatial-resolution is vital to developing new solid catalysts. We demonstrate the application of photoinduced force microscopy (PiFM), with nanometer scale resolution across the infrared spectral range, for the study of zeolite ZSM-5 thin-films with various $\mathrm{Si} / \mathrm{Al}$ ratios after the methanol-to-hydrocarbons reaction. This first-of-its kind nanometer scale infrared imaging of zeolite materials demonstrates the possibility of PiFM for the study of functional porous materials.
\end{abstract}

Zeolite ZSM-5, with the MFI framework topology, plays a pivotal role in petroleum refining and industrial chemical manufacturing, but acquiring nanometer scale insights into its structure-performance relationships in order to engineer superior materials is still a challenge. ${ }^{1,2}$ Recent advances in micro-spectroscopic approaches, such as synchrotron-based infrared (IR) spectroscopy, ${ }^{3,4}$ synchrotron-based X-ray diffraction (XRD), ${ }^{5}$ atom probe tomography (APT), ${ }^{6}$ stimulated Raman scattering $(\mathrm{SRS})^{7}$ and single molecule fluorescence (SMF), ${ }^{8-11}$ have allowed researchers to obtain a more complete picture of the structural and catalytic properties of zeolite catalysts. However, these methods suffer from limitations including the use of probe molecules, being diffraction limited or being inherently destructive techniques. ${ }^{12-15}$ The recently developed, probe molecule-free photoinduced force microscopy (PiFM) can offer a lateral spatial resolution of $\sim 10 \mathrm{~nm}$ and probing depth of $\sim 30 \mathrm{~nm}$ by probing the mid-IR dipole-dipole moment interaction between the atomic force microscopy (AFM) tip and the catalyst (Fig. 1). ${ }^{16,17}$ Herein, the incorporation and spatial distribution of framework $\mathrm{Al}^{3+}$ into zeolite ZSM-5 thin-films

\footnotetext{
${ }^{a}$ Debye Institute for Nanomaterials Science, Faculty of Science, Utrecht University, Universiteitsweg 99, 3584 CG Utrecht, The Netherlands.

E-mail: b.m.weckhuysen@uu.nl;

Web: http://www.inorganic-chemistry-and-catalysis.eu

${ }^{b}$ Molecular Vista Inc., 6840 Via Del Oro, Suite 110, San Jose, CA 95119, USA

$\dagger$ Electronic supplementary information (ESI) available: Experimental details on materials synthesis, characterization and testing, including additional PiFM and CFM data. See DOI: 10.1039/c7cc06832h
}

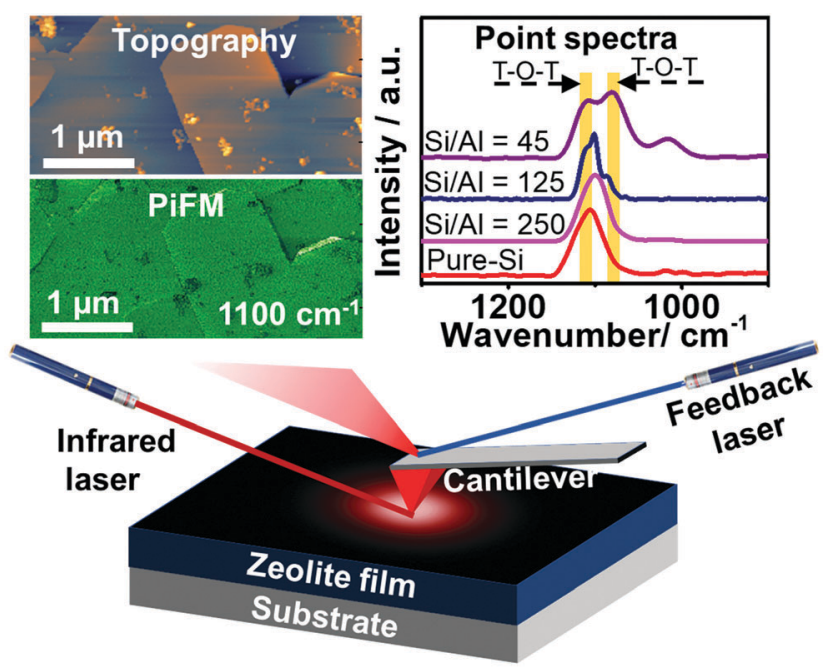

Fig. 1 Schematic of the infrared photoinduced force microscopy (PiFM) experiment. The incident mid-IR laser electrically triggers a dipole-dipole interaction between the zeolite thin-film and atomic force microscopy (AFM) tip. The topography and PiFM signal (image and/or point spectra) of the sample are simultaneously recorded by the AFM feedback system at the second and first mechanical eigenmode resonances of the cantilever, respectively. The sample is raster-scanned under the tip to generate the image. The incident light is polarized along the tip axis to maximize the signal coupling of the dipole-dipole force along the vertical direction of the cantilever vibration. The white scale bar represents $1 \mu \mathrm{m}$.

have been studied using PiFM, and nanometer scale structureperformance relationships have been established by mapping the surface of the zeolite thin-film $(\mathrm{Si} / \mathrm{Al}=45)$ after the methanol-to-hydrocarbons (MTH) reaction.

Zeolite ZSM-5 thin-films, prepared using the secondary growth method by immersing an as-prepared pure-Si monolayer into the secondary growth media (SGM) solutions with various $\mathrm{Si} / \mathrm{Al}$ ratios (i.e. 45, 125, 250 and $\infty$ ) as we reported recently (see Fig. S1, ESI $\dagger$ ), ${ }^{18}$ were studied using PiFM after the MTH reaction at $623 \mathrm{~K}$ for $4 \mathrm{~h}$. Large zeolite ZSM-5 crystals were also studied after a $1.5 \mathrm{~h} \mathrm{MTH}$ reaction $(623 \mathrm{~K})$ to confirm the 

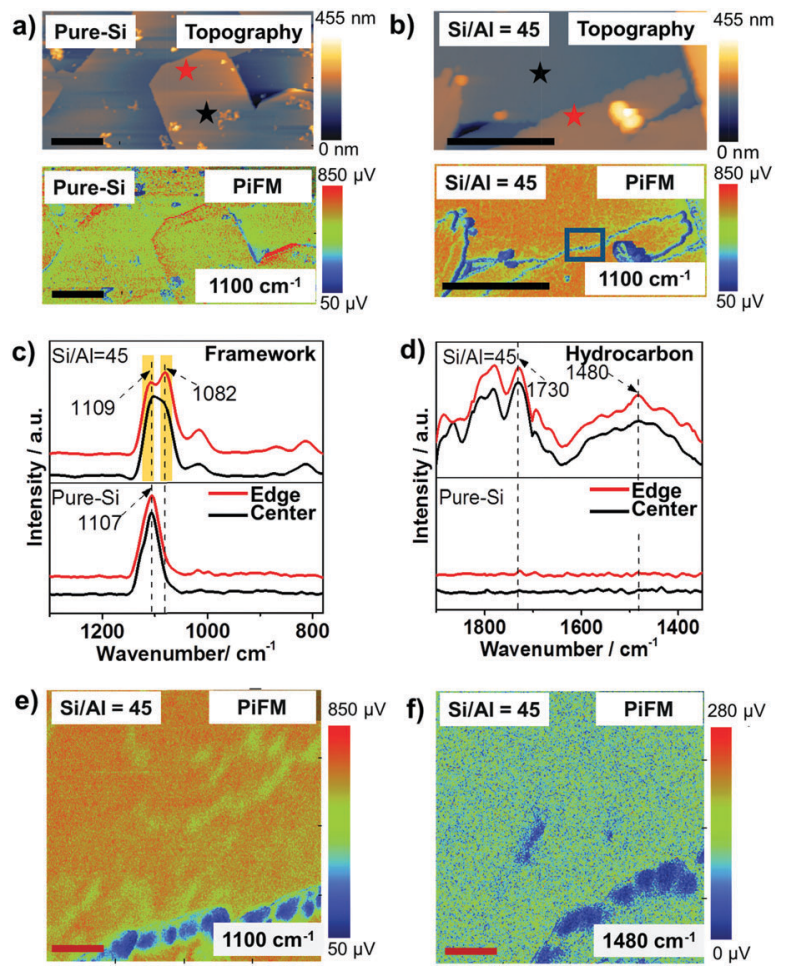

Fig. 2 (a and b) Atomic force microscopy (AFM) topography (top) and photoinduced force microscopy (PiFM, bottom) image at $1100 \mathrm{~cm}^{-1}$ of zeolite ZSM-5 thin-films grown in a secondary growth media with ethanol as the structure directing agent and $\mathrm{Si} / \mathrm{Al}=$ (a) $\infty$ and (b) 45. (c and d) PiFM point spectra show (c) zeolite framework vibration and (d) hydrocarbon vibration distributions at different locations indicated by the stars with corresponding colors in ( $a$ and $b$ ) in the zeolite ZSM-5 thin-films after a $4 \mathrm{~h}$ methanol-to-hydrocarbons (MTH) reaction at $623 \mathrm{~K}$. (e) High resolution PiFM image of the framework vibration at $1100 \mathrm{~cm}^{-1}$ of the zeolite thinfilms from the region highlighted in (b). (f) Product/coke distribution in the same area measured with PiFM at $1480 \mathrm{~cm}^{-1}$ representing the $\mathrm{C}=\mathrm{C}$ stretch of hydrocarbons. The black and red scale bars represent $1 \mu \mathrm{m}$ and $55 \mathrm{~nm}$, respectively. Images (e and f) are shifted with respect to each other due to thermal drift between the tip and the sample.

general utility of the method, further discussed in the ESI. $\dagger^{6}$ As shown in Fig. 2, the surface topography and crystallinity of zeolite thin-films were measured using the AFM mode and PiFM mapping mode, with the zeolite asymmetric framework vibration (T-O-T, $1100 \mathrm{~cm}^{-1}$ ) serving as a marker for the formation of zeolite framework (discussed further in the ESI $\dagger$ ). ${ }^{19,20}$

As shown in Fig. 2a and b, the ethanol-directed pure-Si zeolite thin-film and aluminosilicate zeolite ZSM-5 thin-film with $\mathrm{Si} / \mathrm{Al}=45$ have smooth, well-crystallized surfaces. However, the tetrapropylammonium $\left(\mathrm{TPA}^{+}\right)$directed zeolite ZSM-5 thin-film with $\mathrm{Si} / \mathrm{Al}=45$ has a very rough surface that consists of well-crystallized needle-like zeolite features (Fig. S2, ESI $\dagger$ ), as well as isolated amorphous structures. These observations provide nanometer scale confirmation of the conclusions of our recent work, that ethanol can serve as an overgrowth suppressing structure-directing agent for aluminosilicate ZSM-5 thin-films. ${ }^{18,21}$

Different locations across the aluminosilicate thin-films were also measured with PiFM to examine its sensitivity to framework $\mathrm{Al}^{3+}$ incorporation and its potential for probing nanometer scale
Brønsted acidity variations (based on $\mathrm{Si} / \mathrm{Al}$ ratio) across zeolite thin-films/crystals. In Fig. S3 (ESI $\dagger$ ) we show the gradual red shift from $1107 \mathrm{~cm}^{-1}$ to $1100 \mathrm{~cm}^{-1}$ and finally a split to $\sim 1109$ and $\sim 1082 \mathrm{~cm}^{-1}$ in the asymmetric vibration band in four different thin-films with increasing $\mathrm{Al}$ content, ${ }^{18,22}$ and this can be attributed to the longer $\mathrm{Al}-\mathrm{O}$ bond (1.75 $\mathrm{A})$ than $\mathrm{Si}-\mathrm{O}$ bond $(1.61 \AA)$, as well as the lower mass of $\mathrm{Al}$ compared to $\mathrm{Si}^{5,22-24}$ Fig. 2c compares the known asymmetric framework vibration of zeolites in different locations of the thin-film zeolite crystals, i.e. at the center and the edge, highlighted in Fig. 2a and b. The pure-Si film has a similar peak location and intensity in both locations, while the aluminosilicate thin-film has a different peak intensity ratio of $1082 / 1109 \mathrm{~cm}^{-1}$ bands in different locations, which is attributed to potential differences in the $\mathrm{Al}$ content in the center and at the edge of the aluminosilicate thin-film. These results demonstrate the high sensitivity of PiFM for the examination of heteroatom incorporation and zeolite framework defects.

The product/coke formation from the MTH reaction was studied in the same locations with PiFM, as shown in Fig. 2d, using the $\mathrm{C}=\mathrm{C}$ stretch at $\sim 1480 \mathrm{~cm}^{-1}$ as the fingerprint band of hydrocarbon species. ${ }^{25,26}$ The zeolite thin-film with $\mathrm{Si} / \mathrm{Al}=45$ shows similar hydrocarbon IR spectra at both the center and edge of the crystal, while no hydrocarbon bands were observed in its pure-Si counterpart, demonstrating the bands were the result of the $\mathrm{MTH}$ reaction. Observing a homogeneous distribution of hydrocarbons on the surface, which contains a heterogeneity of $\mathrm{Al}^{3+}$, can be attributed to the long reaction time $(4 \mathrm{~h})$ that resulted in a Brønsted acid site density independent coke deposition. ${ }^{27}$ Interestingly, using confocal fluorescence microscopy (CFM), honeycomb-like fluorescent structures originated from coke species were observed. The differences in the observed hydrocarbon distributions in PiFM and CFM can be attributed to the different probing depths of the two techniques. That is, the PiFM signal is primarily from the surface $(\sim 30 \mathrm{~nm})$, while CFM probes the entirety of the thin films, including the catalytically active regions that are located in the inter-crystal spaces between the pure-Si seed crystals, as shown in Fig. S1 (ESI $\dagger$ ). These findings demonstrate the surface sensitivity of PiFM, and highlight its potential to be employed as a complementary technique to CFM for understanding the catalytic properties of materials at different probing depths, analogous to the use of X-ray photoelectron spectroscopy (XPS) and energy-dispersive X-ray spectroscopy (EDS) to study the surface and bulk Si/Al ratio of zeolite crystals, respectively. ${ }^{28}$ Moreover, the results (Fig. S5, ESI $\dagger$ ) from large crystals after a $1.5 \mathrm{~h}$ MTH reaction show that PiFM can also be applied to study large zeolite crystals, demonstrating the possibility of PiFM for studying other functional porous materials.

A high-resolution analysis of the structure across two connected crystals was conducted by imaging a $220 \times 220 \mathrm{~nm}^{2}$ area to examine the stability and sensitivity of PiFM across this feature. Fig. 2e shows that the crystal has a zeolite framework free edge that is $\sim 20 \mathrm{~nm}$ wide, demonstrated by the weak framework signal, which may be due to the zeolite growth process. A similar feature was previously reported using 
Transmission Electron Microscopy (TEM) and attributed to the assembly by rubbing. ${ }^{29}$ As shown in Fig. 2f, the PiFM image of the same area at $1480 \mathrm{~cm}^{-1}$, the characteristic $\mathrm{C}=\mathrm{C}$ aromatic stretch, shows that the amorphous region is free of product/ coke. Similar results are observed by scanning in the reverse direction, ruling out the possibility that the observation is from the height difference. The results highlight the potential of PiFM for building surface structure-performance relationships with nanometer scale resolution.

This study has explored the nanometer scale framework structure and product/coke distribution in zeolite thin-films using the recently developed PiFM technique. The results suggest that PiFM is highly sensitive to the surface chemical structure with regards to $\mathrm{Al}^{3+}$ framework incorporation. Moreover, with nanometer scale resolution, PiFM demonstrates that an ethanol-directed zeolite $\mathrm{ZSM}-5$ thin-film with $\mathrm{Si} / \mathrm{Al}=45$ has a very smooth surface, while the analogous TPA-directed thinfilm has a very rough surface with highly crystalline needle-like zeolite structures. Additionally, catalytically inactive, amorphous features with a thickness of $\sim 20 \mathrm{~nm}$ at the crystal edge were observed in the ethanol-directed thin-film using PiFM, showing the potential of using this technique to understand zeolite growth mechanisms and develop structure-performance relationships with nanometer scale resolution.

This work is supported by a European Research Council (ERC) Advanced Grant (No. 321140). J. S. has received funding from the European Union's Horizon 2020 research and innovation programme under the Marie Sklodowska-Curie grant agreement No. 702149.

\section{Conflicts of interest}

There are no conflicts to declare.

\section{References}

1 W. Vermeiren and J.-P. Gilson, Top. Catal., 2009, 52, 1131-1161.

2 E. T. C. Vogt, G. T. Whiting, A. Dutta Chowdhury and B. M. Weckhuysen, Adv. Catal., 2015, 58, 143-314.

3 E. Stavitski, M. H. F. Kox, I. Swart, F. M. F. de Groot and B. M. Weckhuysen, Angew. Chem., Int. Ed., 2008, 47, 3543-3547.

4 E. Stavitski and B. M. Weckhuysen, Chem. Soc. Rev., 2010, 39, $4615-4625$.
5 Z. Ristanović, J. P. Hofmann, U. Deka, T. U. Schülli, M. Rohnke, A. M. Beale and B. M. Weckhuysen, Angew. Chem., Int. Ed., 2013, 52, 13382-13386.

6 J. E. Schmidt, J. D. Poplawsky, B. Mazumder, Ö. Attila, D. Fu, D. A. M. de Winter, F. Meirer, S. R. Bare and B. M. Weckhuysen, Angew. Chem., Int. Ed., 2016, 55, 11173-11177.

7 K.-L. Liu, A. V. Kubarev, J. Van Loon, H. Uji-i, D. E. De Vos, J. Hofkens and M. B. J. Roeffaers, ACS Nano, 2014, 8, 12650-12659.

8 K. P. F. Janssen, G. D. Cremer, R. K. Neely, A. V. Kubarev, J. V. Loon, J. A. Martens, D. E. D. Vos, M. B. J. Roeffaers and J. Hofkens, Chem. Soc. Rev., 2014, 43, 990-1006.

9 Z. Ristanović, A. V. Kubarev, J. Hofkens, M. B. J. Roeffaers and B. M. Weckhuysen, J. Am. Chem. Soc., 2016, 138, 13586-13596.

10 K. Kennes, C. Demaret, J. Van Loon, A. V. Kubarev, G. Fleury, M. Sliwa, O. Delpoux, S. Maury, B. Harbuzaru and M. B. J. Roeffaers, ChemCatChem, 2017, 9, 3440-3445.

11 F. C. Hendriks, F. Meirer, A. V. Kubarev, Z. Ristanović, M. B. J. Roeffaers, E. T. C. Vogt, P. C. A. Bruijnincx and B. M. Weckhuysen, J. Am. Chem. Soc., 2017, 139, 13632-13635.

12 E. M. van Schrojenstein Lantman, T. Deckert-Gaudig, A. J. G. Mank, V. Deckert and B. M. Weckhuysen, Nat. Nanotechnol., 2012, 7, 583-586.

13 T. Chen, B. Dong, K. Chen, F. Zhao, X. Cheng, C. Ma, S. Lee, P. Zhang, S. H. Kang, J. W. Ha, W. Xu and N. Fang, Chem. Rev., 2017, 117, 7510-7537.

14 C.-Y. Wu, W. J. Wolf, Y. Levartovsky, H. A. Bechtel, M. C. Martin, F. D. Toste and E. Gross, Nature, 2017, 541, 511-515.

15 Y. Levratovsky and E. Gross, Faraday Discuss., 2016, 188, 345-353.

16 D. Nowak, W. Morrison, H. K. Wickramasinghe, J. Jahng, E. Potma, L. Wan, R. Ruiz, T. R. Albrecht, K. Schmidt, J. Frommer, D. P. Sanders and S. Park, Sci. Adv., 2016, 2, e1501571.

17 R. A. Murdick, W. Morrison, D. Nowak, T. R. Albrecht, J. Jahng and S. Park, Jpn. J. Appl. Phys., 2017, 56, 08LA04.

18 D. Fu, J. E. Schmidt, Z. Ristanović, A. D. Chowdhury, F. Meirer and B. M. Weckhuysen, Angew. Chem., Int. Ed., 2017, 56, 11217-11221.

19 W. Guo, J. Liang, H. Li, M. Ying and J. Hu, Stud. Surf. Sci. Catal., 1985, 24, 279-286.

20 J. C. Jansen, F. J. van der Gaag and H. van Bekkum, Zeolites, 1984, 4, 369-372.

21 E. Costa, M. A. Uguina, A. de Lucas and J. Blanes, J. Catal., 1987, 107, 317-324.

$22 \mathrm{X}$. Liu, in Zeolite Characterization and Catalysis, ed. A. W. Chester and P. E. G. Derouane, Springer, Berlin, 2009, pp. 197-222.

23 E. M. Flanigen, H. Khatami and H. A. Szymanski, in Molecular Sieve Zeolites-I, ed. E. M. Flanigen and L. B. Sand, American Chemical Society, Washington, DC, 1974, vol. 101, pp. 201-229.

24 L. Shirazi, E. Jamshidi and M. R. Ghasemi, Cryst. Res. Technol., 2008, 43, 1300-1306.

25 Q. Qian, C. Vogt, M. Mokhtar, A. M. Asiri, S. A. Al-Thabaiti, S. N. Basahel, J. Ruiz-Martínez and B. M. Weckhuysen, ChemCatChem, 2014, 6, 3396-3408.

26 J. W. Park and G. Seo, Appl. Catal., A, 2009, 356, 180-188.

27 D. Mores, J. Kornatowski, U. Olsbye and B. M. Weckhuysen, Chem. - Eur. J., 2011, 17, 2874-2884.

28 S. Fibikar, M. T. Rinke, A. Schäfer and L. De Cola, Microporous Mesoporous Mater., 2010, 132, 296-299.

29 T. C. T. Pham, H. S. Kim and K. B. Yoon, Science, 2011, 334, 1533-1538. 